\title{
Wear-Resistant Ultrahigh-Molecular-Weight Polyethylene-Based Nano- and Microcomposites for Implants
}

\author{
S. V. Panin, ${ }^{1,2}$ L. A. Kornienko, ${ }^{1}$ N. Sonjaitham, ${ }^{2}$ M. V. Tchaikina, ${ }^{3}$ \\ V. P. Sergeev, ${ }^{1}$ L. R. Ivanova, ${ }^{1}$ and S. V. Shilko ${ }^{4}$ \\ ${ }^{1}$ Institute of Strength Physics and Materials Science SB RAS, Laboratory of Composite Polymeric Materials, pr. Akademicheskii, 2/4, \\ Tomsk 634021, Russia \\ ${ }^{2}$ National Research Tomsk Polytechnic University, Institute of Physics of High Technologies, Lenin Avenue, 30, Tomsk 634050, Russia \\ ${ }^{3}$ Institute of Solid State Chemistry and Mechanochemistry SB RAS, Laboratory of Intercalation and Mechanochemical Reactions, \\ Kutateladze 18, Novosibirsk 630128, Russia \\ ${ }^{4}$ V.A. Belyi Metal-Polymer Research Institute NASB, Department of Mechanics of Adaptive Materials and Biomechanics, \\ 32A Kirov Street, 246050 Gomel, Belarus
}

Correspondence should be addressed to S. V. Panin, paninsergey@yahoo.co.uk

Received 10 April 2012; Accepted 18 May 2012

Academic Editor: Guifu Zou

Copyright $\odot 2012$ S. V. Panin et al. This is an open access article distributed under the Creative Commons Attribution License, which permits unrestricted use, distribution, and reproduction in any medium, provided the original work is properly cited.

\begin{abstract}
The influence of modification by hydroxyapatite (HA) nano- and microparticles on tribotechnical properties of ultrahighmolecular-weight polyethylene (UHMWPE) was investigated to develop polymer implants for endoprosthesis. It was shown that modification of UHMWPE by hydroxyapatite nanoparticles within range of $0.1-0.5 \mathrm{wt} . \%$ results in increase of wear resistance at dry sliding by 3 times. On the other hand adding of $20 \mathrm{wt} . \%$ of micron size HA gives rise to the same effect. The effect of increasing wear resistance is not substantially changed at surface treatment of the nano- and microcomposites by $\mathrm{N}^{+}$ion beams as compared with nonirradiated blends. Preliminary joint mechanical activation of UHMWPE powder and fillers results in more uniform distribution of nanofillers in the matrix and, as a result, formation of more ordered structure. Structure within bulk material and surface layers was studied by means of optical profilometry, scanning electron microscopy, infrared spectroscopy, and differential scanning calorimetry. It is shown that adding of hydroxyapatite nanoparticles and high-energy surface treatment of the composite by $\mathrm{N}^{+}$ion implantation improve tribotechnical properties of UHMWPE due to formation of chemical bonds in the composite (crosslinking) and ordering of permolecular structure.
\end{abstract}

\section{Introduction}

Since having relatively high strength characteristics, low friction factor, high wear and chemical resistance in corrosive media ultrahigh-molecular-weight polyethylene (UHMWPE) is used for the manufacturing of implants (artificial joints, face surgery, etc.). The reason for its wide use as a material for implants is related to its similarity to biotissues on chemical nature and physical-mechanical properties [1-4]. UHMWPE-based nanocomposites with biocompatible fillers are currently not well-studied objects in the modern medical materials science [5-9]. The variety of biocompatible filler is extremely limited. In [10] which is to date the most comprehensive handbook on manufacturing and operation of UHMWPE in medical practice, the focus is done on the improvement tribotechnical properties of this polymer by means of ion implantation that is generally combined with the procedure of sterilization. However, reinforcement of polymeric materials for medical applications is mostly limited by using HA particles. In doing so the optimum weight fraction is still a matter of systematic investigations. Hydroxyapatite (HA or calcium hydroxyl phosphate ) $\left(\mathrm{C}_{10}\left(\mathrm{PO}_{4}\right)_{6}(\mathrm{OH})_{2}\right)$ belongs to the class of biologically active materials with properties of high surface activity, high biocompatibility which are similar to the bone matrix structure providing reliable fixation of implants.

From the point of view of HA use as a prospective filler for bioimplants it should be noted that presence of micronsize HA particles during interaction of the filled polymer with articular fluid will be accompanied by their gradual 
TABLE 1: Mechanical properties of nano- and microcomposites based on UHMWPE.

\begin{tabular}{lccc}
\hline Content of HA filler, wt.\% & Density, $\mathrm{g} / \mathrm{sm}^{3}$ & Strength, MPa & Elongation, \% \\
\hline 0 & 0.936 & 33.5 & 380.4 \\
Nano $(20-30 \mathrm{~nm})$ & & & 29.6 \\
0.1 & 0.935 & 32.4 & 430.6 \\
0.5 & 0.937 & 31.4 & 492.3 \\
1 & 0.939 & 32.6 & 461.3 \\
2 & 0.944 & & 398.5 \\
Micro $(7-8 \mu \mathrm{m})$ & & 26.9 & 473.8 \\
5 & 0.954 & 31.7 & 433.7 \\
10 & 0.986 & 25.8 & 231.1 \\
20 & 1.071 & 14.2 & \\
40 & 1.095 & & \\
\hline
\end{tabular}

resorption and formation of micron-size pore skeleton which is adversely affecting the strength and wear resistance. Adding of the nanosize hydroxyapatite particles will provide formation of porous nanoskeleton that should not reduce the strength properties and will be accompanied by the accumulation of synovial liquid within the pores. The liquid will be partly allocated at the interface of plastic cup and metal ( $\mathrm{CoNiCr}$ ) head hip prostheses, to reduce the intensity of polymer wear by several times $[1,2]$.

Certain prospects at obtaining materials for manufacturing implants with high mechanical and tribotechnical properties might be found in the area of combined use of biocompatible fillers and high energy electron beam treatment of composites. However, studies of UHMWPEbased composites to be performed at combined use of various methods for treatment of polymer composites for medical applications at present are hardly to be found in the literature.

In this work physical-mechanical and tribotechnical characteristics of UHMWPE-based composites with biocompatible nano- and microfillers based on hydroxyapatite were studied. Comparative analysis of wear resistance of nano- and microcomposites as well as influence of highenergy treatment (ion implantation) of the above-mentioned composites on their wear resistance was carried out.

\section{Experimental}

In the paper the powder of UHMWPE (GUR-2122 by Ticona) with molecular weight of 4.0 million and its composites with various weight fraction of $\mathrm{HA}\left(\mathrm{C}_{10}\left(\mathrm{PO}_{4}\right)_{6}(\mathrm{OH})_{2}\right)$ nano- and microparticles were used. The size of nanoparticles obtained by mechanosynthesis made $20-30 \mathrm{~nm}$ while microparticles obtained by grinding animal bones made 7 $8 \mu \mathrm{m}$. Specimens of polymer composites were obtained by hot pressing at specific pressure of $10 \mathrm{MPa}$, temperature of $190^{\circ} \mathrm{C}$ and cooling rate of $3-4^{\circ} \mathrm{C} / \mathrm{min}$. Industrial type planetary ball mill MR/0.5 * 4 [11] was employed for powder mechanical activation as well as mixing of UHMWPE polymeric binder and fillers.

Ion implantation by $\mathrm{N}^{+}$ions was carried out using "DIANA-2" setup (fluence of 0.5, 1 and $2 * 10^{17} \mathrm{ion} / \mathrm{cm}^{2}$ ) at accelerating voltage of $60 \mathrm{kV}$, with ion beam current amplitude of $490 \mathrm{~mA}$ and pulse frequency $50 \mathrm{~Hz}$. Wear resistance of test materials under dry sliding was determined by "block-on-ring" scheme at load of $160 \mathrm{~N}$ and revolution rate $100 \mathrm{rpm}$ in accordance with ASTM G99 and DIN 50324 with the use of SMT-1 machine. Size of specimens made $7 \times 7 \times 10 \mathrm{~mm}^{3}$. Diameter of the roller made $62 \mathrm{~mm}$.

Wear track surfaces were investigated with the use of optical profilometer Zygo New View 6200. Wear track area was estimated with the help of "Rhino Ceros 3.0" software by manual allocation of wear track contour and subsequent automated calculation. Measurements of degree of crystallinity were performed by the help of SDT Analyzer Q600. Infrared spectra were registered by FTIR spectrometer NIKOLET 5700. Structure investigations were performed using scanning electron microscope LEO EVO 50 at acceleration voltage of $20 \mathrm{kV}$ on surface of fractured specimens failing just after extracting them from liquid nitrogen.

\section{Results and Discussion}

The data to summarize results of measuring mechanical properties of UHMWPE-based composites with microand nanofillers are presented in Table 1. The data show that ultimate strength is decreased when polymer is filled by either nano- or microfillers, but it does not depend on volume fraction of the fillers. In doing so, elongation at tension is increased as filler weight fraction is enlarged while this also weakly depends on nanofillers weight fraction. It can be seen that $0.5 \mathrm{wt}$. $\%$ of HA to be added into nanocomposite is enough to reach the optimum (maximum) values of strength and ductility. Mechanical properties of the composites are decreased sharply when the HA (micro) weight fraction exceeds $20 \mathrm{wt} \%$.

In terms of tribotechnical characteristics the influence of variation weight fraction of the hydroxyapatite filler possesses different trend. Curves of kinetic wear for all tested composites are presented in Figure 1, while wear intensity $\left(I, \mathrm{~mm}^{2} / \mathrm{min}\right)$ diagram of the composites under study to be measured at steady-state wearing stage is depicted in Figure 2. One can see that wear resistance of UHMWPE with the volume fraction of nanoparticles of $0.1-0.5 \mathrm{wt} . \%$ 


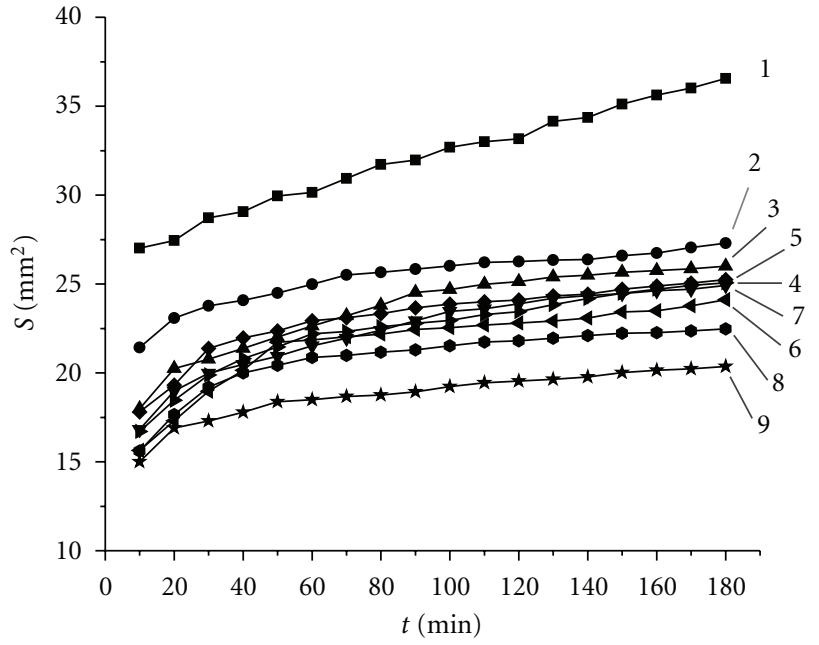

FIgURE 1: Kinetic wear curves of UHMWPE-based specimens: (1) pure UHMWPE; nanocomposites: UHMWPE +0.1 (2), +0.5 (3), +1 (4), +2 (5) wt.\% HA and microcomposites UHMWPE: +5 (6), +10 (7), +20 (8), +40 (9) wt.\% HA.

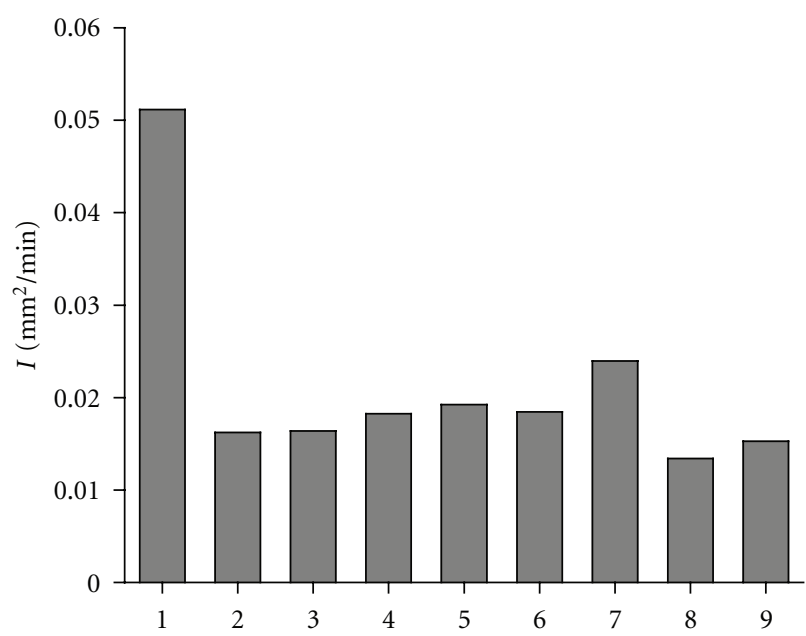

Figure 2: Wear intensity $(I)$ of specimens: pure UHMWPE (1), nanocomposites UHMWPE +0.1 (2), 0.5 (3), 1 (4), 2 (5) wt.\% HA and microcomposites UHMWPE +5 (6), 10 (7), 20 (8), 40 (9) wt.\% $\mathrm{HA}$ at the steady-state wearing stage.

is increased by 3.5 times. Wear resistance of the specimens is decreased (columns 4, 5) when the weight fraction of nanoparticles is increased up to $1-2 \mathrm{wt} \%$. In doing so, wear resistance of nanocomposites with HA volume fraction of $0.1-0.5 \mathrm{wt} . \%$ is approximately equal to one of composites with $20 \mathrm{wt} . \%$ of HA micron size filler (columns $2,8)$.

Dependence of wear track surface roughness $(\mathrm{Ra}, \mu \mathrm{m})$ as a function of the filler (nano- and micro-) weight fraction in the composites is the same (Figure 3). Therefore, further analysis on the influence of high energy treatment $\left(\mathrm{N}^{+}\right.$ ion implantation) was carried out for the nanocomposites UHMWPE + 0.5 wt. \% HA and microcomposites UHMWPE +20 wt. $\%$ HA.

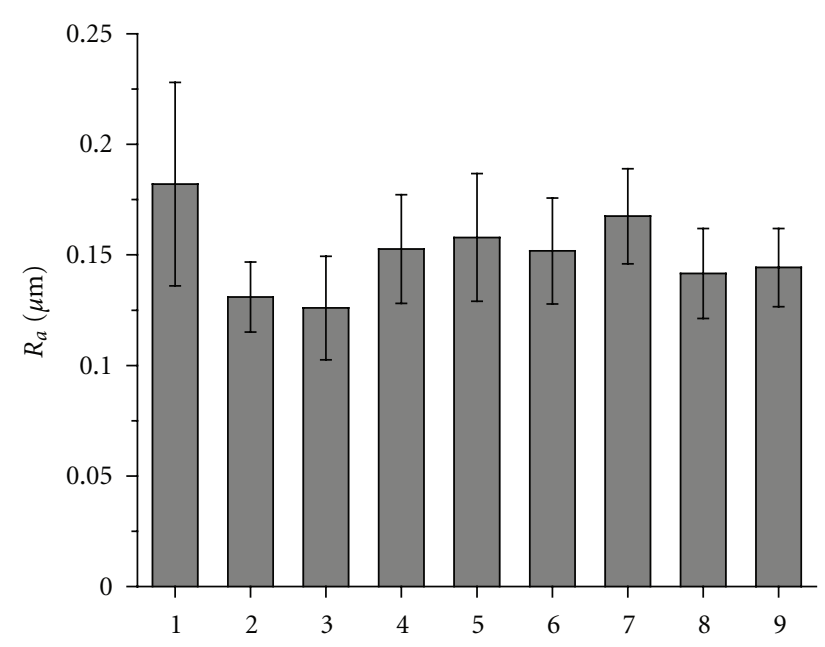

FIGURE 3: Dependence of surface roughness of wear track (Ra) in pure UHMWPE (1), nanocomposites UHMWPE +0.1 (2), 0.5 (3), 1 (4), 2(5) wt.\% HA and microcomposites UHMWPE +5 (6), 10 (7), 20 (8), 40 (9) wt.\% HA at the steady-state wearing stage.

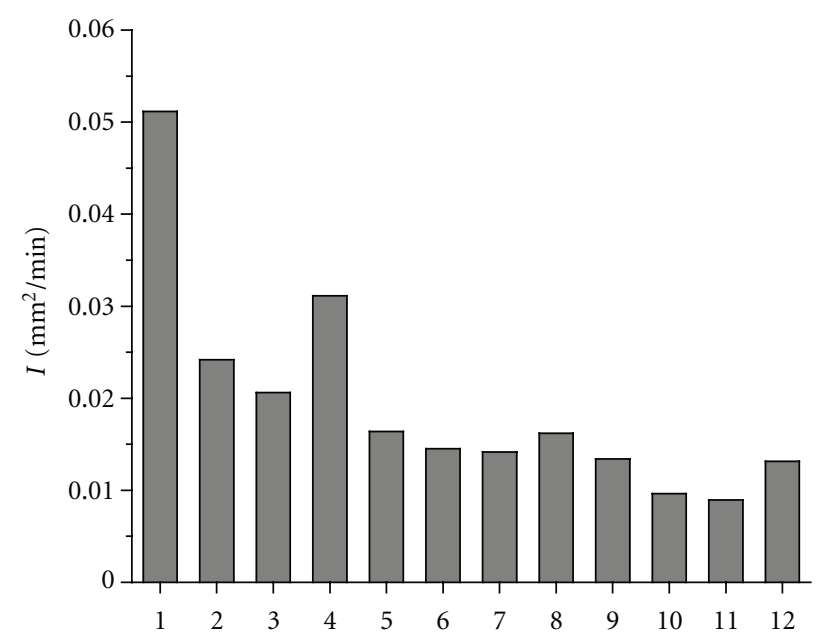

FIgURe 4: Wear intensity $(I)$ of UHMWPE specimens: pure (1) and $\mathrm{N}^{+}$ion implanted with doses of $0.5(2), 1(3), 2 \cdot 10^{17}(4)$; nanocomposites UHMWPE $+0.5 \mathrm{wt} . \% \mathrm{HA}$ in the initial state (5) and implanted one with doses $0.5(6), 1(7), 2 \cdot 10^{17} \mathrm{~N}^{+}(8)$; microcomposites UHMWPE + 20 wt. $\%$ HA without surface treatment (9) and implanted ones with doses of $0.5(10), 1(11), 2 \cdot 10^{17} \mathrm{~N}^{+}(12)$ at the steady-state wearing stage.

Analysis of wear intensity of composites implanted by $\mathrm{N}^{+}$ions has shown that, firstly, the optimum fluence made $1 \cdot 10^{17} \mathrm{ion} / \mathrm{cm}^{2}$ both for the nonfilled polymer (Figure 4, columns 1-4) and for the composites (Figure 4, columns 5-8, and 9-12). Secondly, for the unfilled UHMWPE specimens wear resistance at ion implantation is increased by three times, whereas for composites (nano and micro) only by $10-30 \%$. Thirdly, wear resistance of implanted microcomposites (UHMPE +20 wt.\% HA) is slightly higher than that in nanocomposites (columns 7 and 11). Roughness of wear track surface of the implanted UHMPE specimens and composites on its basis is presented in Figure 5. 
TABLE 2: Crystallinity $(\chi, \%)$ in UHMWPE-based composites.

\begin{tabular}{lcc}
\hline UHMWPE & 0.5 wt.\% HA (nano) & 20 wt.\% HA (micro) \\
\hline 56.6 & 41.1 & 41.4 \\
60.2 & 48.9 & 46.8 \\
\hline
\end{tabular}

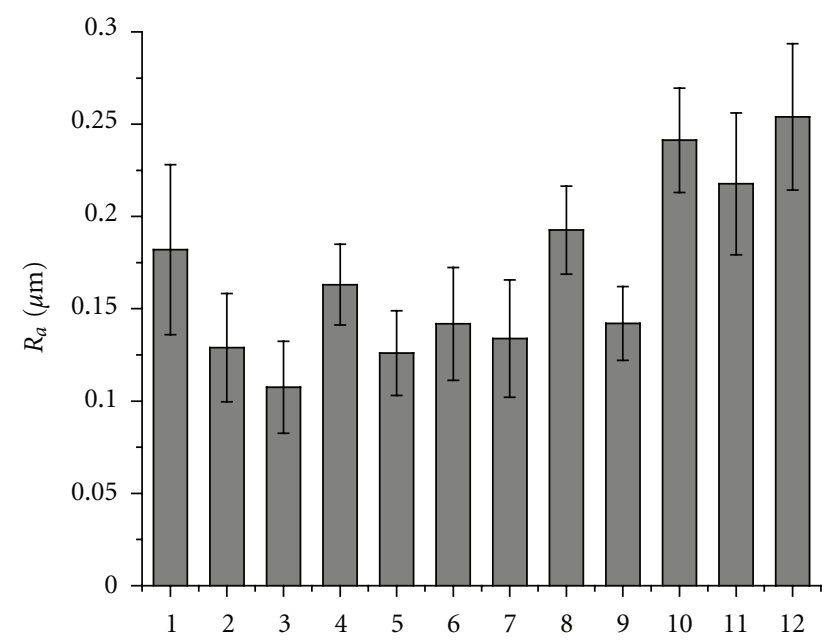

FIGURE 5: Dependence of surface roughness of wear track $(\mathrm{Ra})$ of specimens under tests: pure UHMWPE (1), $\mathrm{N}^{+}$implanted UHMWPE with dozes: 0.5 (2), 1 (3), $2 \cdot 10^{17}$ (4); nanocomposites: UHMWPE $+0.5 \mathrm{wt} \%$ HA without surface treatment (5) and implanted with dozes $0.5(6), 1(7), 2 \cdot 10^{17} \mathrm{~N}^{+}(8)$; microcomposites: UHMWPE +20 wt. $\%$ HA without ion implantation (9) and implanted with dozes $0.5(10), 1(11), 2 \cdot 10^{17} \mathrm{~N}^{+}(12)$ at the steadystate wearing stage.

Comparative analysis of permolecular structure to result from filling polymer by various sizes hydroxyapatite particles and subsequent high energy $\mathrm{N}^{+}$ion beam treatment of different doses was made to clarify the mechanism of improving wear resistance of UHMWPE-based nano- and microcomposites. The results of measurement of crystallinity degree of pure UHMWPE and composites on its basis (raw 2) and implanted ones with fluence of $1-10^{17} \mathrm{ion} / \mathrm{cm}^{2}$ (raw 3), obtained by the method of differential scanning calorimetry (DSC), are presented in Table 2.

As becomes clear from Table 2, the filling of the polymer by HA nano- and microparticles results in decrease of composite crystallinity. The latter in the surface layer (raw 3 ) is increased due to the $\mathrm{N}^{+}$ions surface treatment of the UHMWPE specimens and the composites. Permolecular structure of the pure UHMWPE is spherulitic one (Figure $6(\mathrm{a}))$. Filling of polymer by HA nanoparticles does not alter the nature of the permolecular structure (Figure 6(b)). At the same time microfillers suppress the formation of spherulitic permolecular structure (Figures 6(c) and 6(d)).

The ion treatment of UHMWPE specimen surface and its composites causes structure change in the surface layer (Figure 7). The depth of the modified surface layer with lamellar permolecular structure in the nanocomposite UHMWPE +0.5 wt. \% HA is less than that in the implanted UHMWPE and makes 500-800 $\mu \mathrm{m}$. In our view, nanofiller shields the rearrangement of macromolecules under the high-energy effect. As a result the permolecular structure in deeper layers becomes amorphous (jelly-like) (Figures 7(a) and 7(b)). Structurally modified layer in the microcomposites UHMPE $+20 \mathrm{wt} . \%$ is extremely thin, and crystallinity (structural order) also slightly increases (Table 2).

IR-spectra of bulk material and surface layers of the polymer specimens were studied before and after the implantation for more detailed analysis of structural changes to take place in the UHMWPE specimens and (nano- and micro-) composites on its basis. IR-spectra for pure UHMWPE and its composites UHMWPE $+0.5 \mathrm{wt} \% \mathrm{HA}$ (nano) and UHMWPE + 20 wt. \% HA (micro) are given in Figure 8 for the sake of comparison. One can see that the intensities of carbonyl group peaks 1700, 1620, 1040, and $1240 \mathrm{~cm}^{-1}$ relevant to $\mathrm{C}=\mathrm{O}, \mathrm{C}=\mathrm{C}$ and $\mathrm{C}-\mathrm{O}-\mathrm{C}, \mathrm{C}-\mathrm{C}-\mathrm{O}$ bonds [4] are increased in the spectrum of filled specimens. In doing so, nanofiller tends to be more active (Figure 8 , curve 2 ). In the regions 2250, 3200, 3300, $3500 \mathrm{~cm}^{-1}$ there occur bonds of the $\mathrm{C}=\mathrm{N}, \mathrm{N}-\mathrm{H}, \mathrm{O}-\mathrm{H}$ type which are missing in the spectra of the nanocomposite (Figure 8, curve 3). Surface treatment of the nanocomposites by $\mathrm{N}^{+}$ions does not change the general pattern of the spectrum (Figure 9). The intensity of the above-mentioned bonds in the surface layer of the specimen treated by ion beam becomes lower. The same pattern is observed in the surface layer of microcomposites treated by ion beam. In doing so, the crystallinity in the surface layer of implanted nano- and microcomposites increases in comparison with one in untreated specimens (Table 2), which is related to increased wear resistance of UHMWPE and UHMWPE-based composites due to the implantation of $\mathrm{N}^{+}$ions (Figure 4). It should be noted that the treatment of the pure UHMWPE by ion beam is more efficient than implantation of UHMWPE-based composites. Nano- and micro-HAs hinder macromolecules rearrangement in a surface layer caused by high energy effect. Therefore, as a result of the ion implantation, the depth of the modified surface layer is highest in pure UHMWPE. As for the nanocomposites it is decreased, while for the microcomposites it has minimum thickness.

The comparative analysis of two methods of highenergy treatment of UHMWPE surface and nanocomposites based on its basis (ion implantation and electron beam treatment) has been performed. Influence of electron beam on wear resistance of UHMWPE and nanocomposites on its basis has been previously described in [4]. Analysis of tribotechnical characteristics and structural changes in a bulk material and surface layers after high-energy treatments showed that wear resistance of UHMWPE after electron beam treatment at steady-state stage of wear is equivalent the wear resistance of ion-implanted UHMWPE with the dose of $1 \cdot 10^{17} \mathrm{ion} / \mathrm{cm}^{2}\left(\mathrm{~N}^{+}\right)$. This is due to an identity of permolecular (lamellar) structure being formed in the surface layer of polymer under the high-energy effect.

As was shown by analysis made in this paper as well as in [4] the permolecular structure formed is similar to one in UHMWPE after mechanical activation [11]. As a result, wear resistance of UHMWPE after electron-beam 


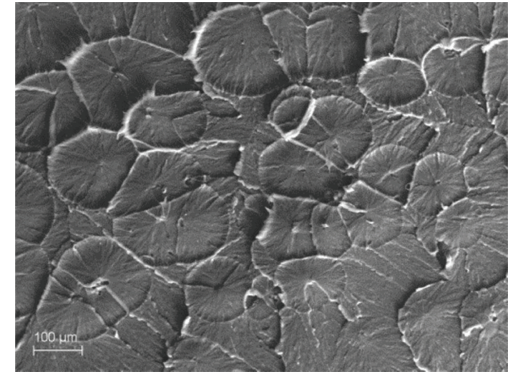

(a)

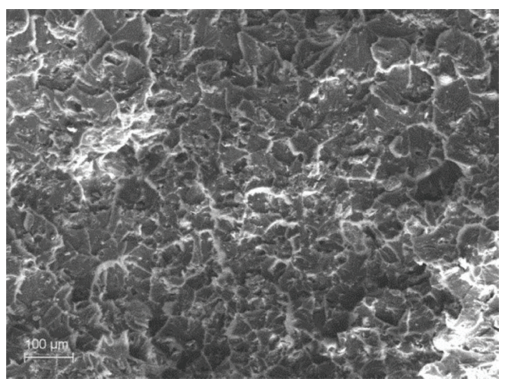

(c)

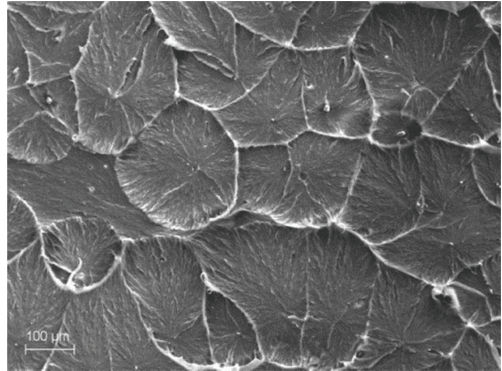

(b)

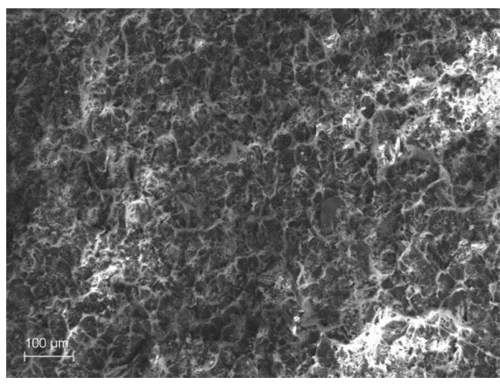

(d)

Figure 6: Permolecular structure of the pure UHMWPE (a), nanocomposite UHMWPE $+0.5 \mathrm{wt} . \%$ HA (b) and microcomposites: UHMWPE + 10 wt. $\%$ HA (c), UHMWPE + 20 wt. $\%$ HA (d).

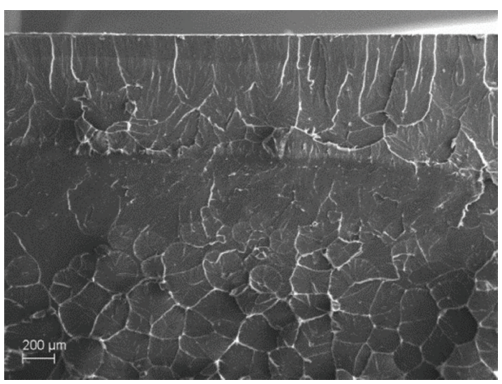

(a)

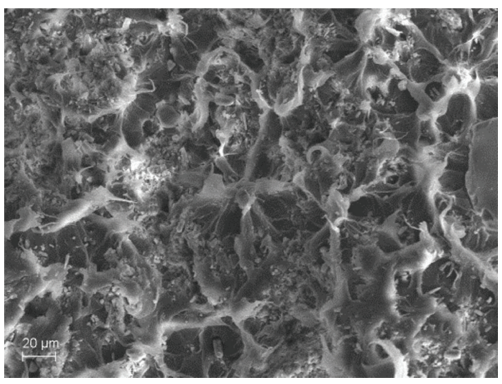

(c)

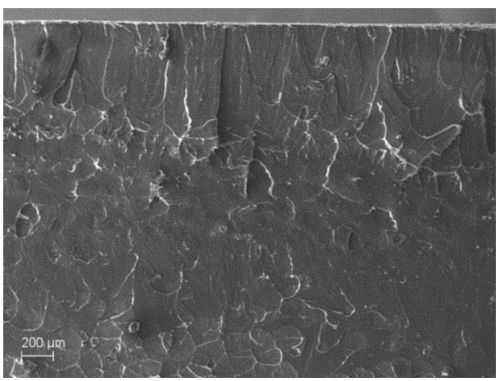

(b)

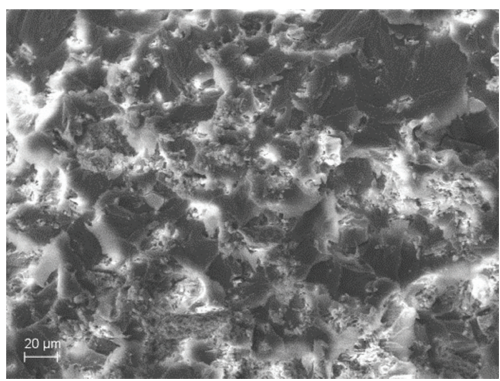

(d)

FIGURE 7: Permolecular structure of the implanted UHMWPE (a), nanocomposite UHMWPE +0.5 wt.\% HA (b) and microcomposites: UHMWPE + 10 wt. $\%$ HA (c), UHMWPE + 20 wt. $\%$ HA (d). Dose: $\mathrm{N}^{+} 1 \cdot 10^{17}$.

treatment and ion implantation at steady-state wearing stage is similar to one of the polymer after mechanical activation. So, the electron-beam surface treatment of UHMWPE and mechanical activation can be used as equivalent ways to increase wear resistance of polymer.
In contrast with our previous data the characteristic feature of HA as a filler for UHMWPE is its chemical and surface activity that gives rise to chemical bonding with the polymer [12]. HA microfiller demonstrates these properties to a less extent (Figure 8). Therefore, the effectiveness of 


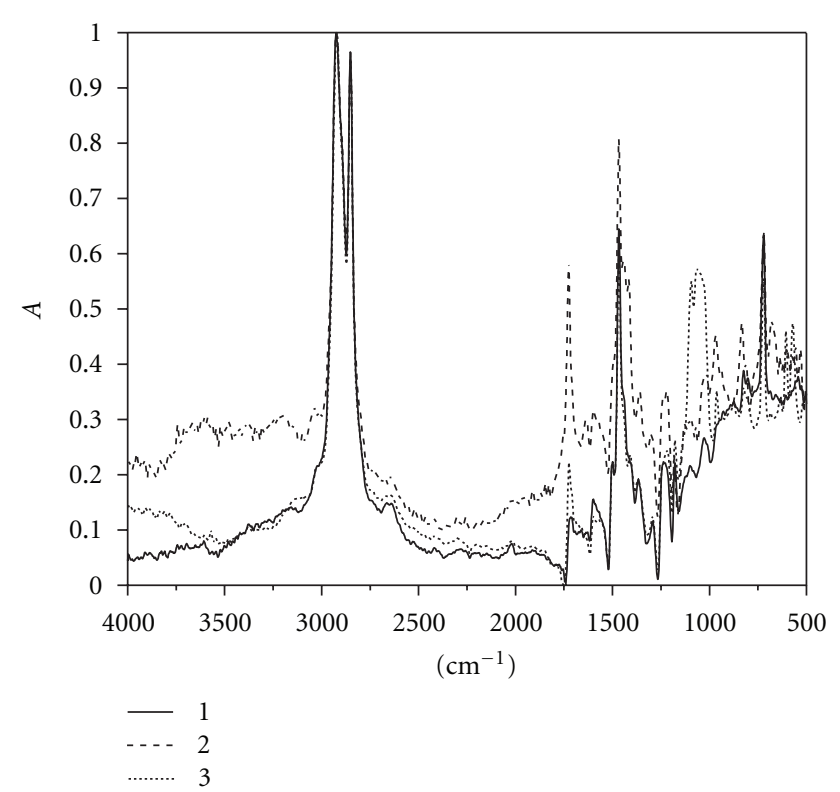

Figure 8: IR spectra of pure UHMWPE (1), UHMWPE-based nanocomposite (with 0.5 wt.\% HA) (2) and UHMWPE-based microcomposite (with $20 \mathrm{wt} . \% \mathrm{HA}$ ) (3).

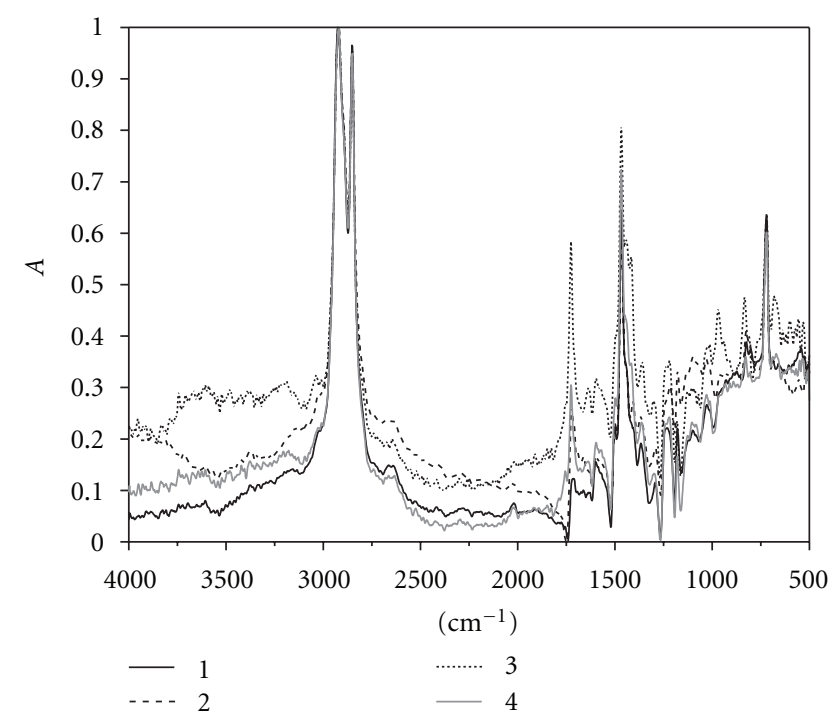

FIGURE 9: IR spectra of pure UHMWPE (1), implanted UHMWPE (2), UHMWPE-based nanocomposite (with 0.5 wt. \% HA) (3), UHMWPE-based mictocomposite (with 20 wt. \% HA) (4). Dose: $\mathrm{N}^{+} 1 \cdot 10^{17}$.

the electron-beam surface treatment of the UHMWPE-based composites (with nano- and micro-HA) to increase wear resistance is low being compared with one of the pure UHMWPE $[13,14]$. Hardening due to formation of chemical bonds (crosslinking) is realized by adding HA nanofillers. Electron-beam surface treatment of the UHMWPE-based composites gives only to slight additional crosslinking of molecules providing complimentary sterilization of specimens (items for medical use).
On the other hand, HA nanofillers "oscillating" in a destructurized surface layer of composite and synovial fluid of a joint eventually create a porous nanoframework filled by synovial fluid [1]. Composite with a weight fraction of $20 \mathrm{wt}$ \% HA microfiller are capable of similar wear resistance, but it will bring to the gradual resorption and formation of micron-sized pores framework which will adversely affect the strength and wear resistance. Since HA fillers partially shield rearrangement of a structure, crosslinking of macromolecules (their ordered packing) which is the main mechanism for improving its wear resistance [15], the highenergy surface treatment of nanocomposites can be used in combination with nanofilling as well as a method of sterilization.

\section{Conclusion}

(i) Nanofilling of UHMWPE by $0.1-0.5 \mathrm{wt} . \% \mathrm{HA}$ increases its wear resistance in 3.5 times compared to the pure polymer. Adding of $20 \mathrm{wt} . \%$ HA micron size particles provides the similar wear resistance.

(ii) High-energy treatment by $\mathrm{N}^{+}$ion beam brings structural rearrangement and crosslinking of macromolecules in the polymer surface layers resulting in increase of its wear resistance. HA fillers "shield" structural rearrangement in the surface layers and only slightly increase the wear resistance of composites.

(iii) Wear resistance of ion-implanted UHMWPE and composites on its basis is comparable with the one after the electron-beam treatment that caused the identity of permolecular structure modification of surface layers under the high-energy effect.

(iv) The high-energy treatment of UHMWPE-based composites can be used in combination with filling by HA nanoparticles of as a method of sterilization of products for medical applications (orthopaedic implants).

\section{References}

[1] L. S. Pinchuk, M. Y. Chernyakova, and V. À. Goldade, "Tribology of joints and the problems of modern orthopedics," Journal of Friction and Wear, vol. 29, no. 3, pp. 224-233, 2008.

[2] L. S. Pinchuk, "Modern trends in evolution of joint endoprostheses," in Proceedings of the 14th International Colloquium Tribology, vol. 3 of Tribology and Lubrication Engineering, pp. 1735-1739, Technische Academie Esslingen, Ostfildern, Germany, January 2004.

[3] S. V. Panin, L. À. Kornienko, Ò. Poowadin, V. P. Sergeev, L. R. Ivanova, and S. V. Shilko, "Friction and Wear of the ion-implanted ultra-high molecular weight polyethylene for implants," Trenie i Smazka v Machinakh i Mekhanizmakh, no. 10, pp. 3-12, 2010 (Russian).

[4] O. N. Tretinnikov and Y. Ikada, "Surface characterization of ion-implanted polyethylene," Journal of Polymer Science, Part B, vol. 36, no. 4, pp. 715-725, 1998. 
[5] S. V. Panin, L. À. Kornienko, Ò. Poowadin et al., "Friction and wear of the ultra-high molecular weight polyethylene modified by electron-beam high-energy treatment," Trenie $i$ Smazka v Machinakh i Mekhanizmakh, no. 12, pp. 26-31, 2011 (Russian).

[6] N. K. Myshkin, M. I. Petrokovets, and A. V. Kovalev, "Tribology of polymers: adhesion, friction, wear, and mass-transfer," Tribology International, vol. 38, no. 11-12, pp. 910-921, 2005.

[7] S. M. Lee, S. W. Choi, Y. C. Nho, and H. H. Song, "Modification of microstructures and physical properties of ultra high molecular weight polyethylene by electron beam irradiation," Journal of Polymer Science, Part B, vol. 43, no. 21, pp. 3019-3029, 2005.

[8] A. M. Avilov, V. A. Deryga, and G. F. Popov, "Composite materials formation for orthopaedic implants," Problems of Atomic Science and Technology, no. 1, pp. 181-183, 2004.

[9] J. Zhou and F. Yan, "Improvement of the tribological behavior of ultra-high-molecular-weight polyethylene by incorporation of poly (phenyl p-hydroxyzoate)," Journal of Applied Polymer Science, vol. 96, no. 6, pp. 2336-2343, 2005.

[10] S. M. Kurtz, The UHMWPE Handbook: Ultra-High Molecular Weight Polyethylene in Total Joint Replacement, Academic Press, 2004.

[11] V. E. Panin, S. V. Panin, L. A. Kornienko, S. Vannasri, L. R. Ivanova, and S. V. Shil'ko, "Effect of mechanical activation of ultra-high-molecular-weight polyethylene on its mechanical and triboengineering properties," Journal of Friction and Wear, vol. 31, no. 2, pp. 121-127, 2010.

[12] S. V. Panin, L. A. Kornienko, S. Vannasri et al., "Comparison of the efficiency of modification of SHMPE by nanofibers $\left(\mathrm{C}, \mathrm{Al}_{2} \mathrm{O}_{3}\right)$ and nanoparticles $\left(\mathrm{Cu}, \mathrm{SiO}_{2}\right)$ when obtaining antifriction composites," Journal of Friction and Wear, vol. 31, no. 6, pp. 460-468, 2010.

[13] A. Toth, I. Bertoti, E. Szilagy et al., "Surface characterization of ultrahigh molecular weight polyethylene after nitrogen ion implantation," Surface and Interface Analysis, vol. 30, pp. 434438, 2000.

[14] S. R. Sinha and B. J. Briscoe, Polymer Tribology, Imperial college Press, London, UK, 2009.

[15] J. R. Cooper, D. Dowson, and J. Fisher, "Macroscopic and microscopic wear mechanisms in ultra-high molecular weight polyethylene," Wear, vol. 162-164, pp. 378-384, 1993. 

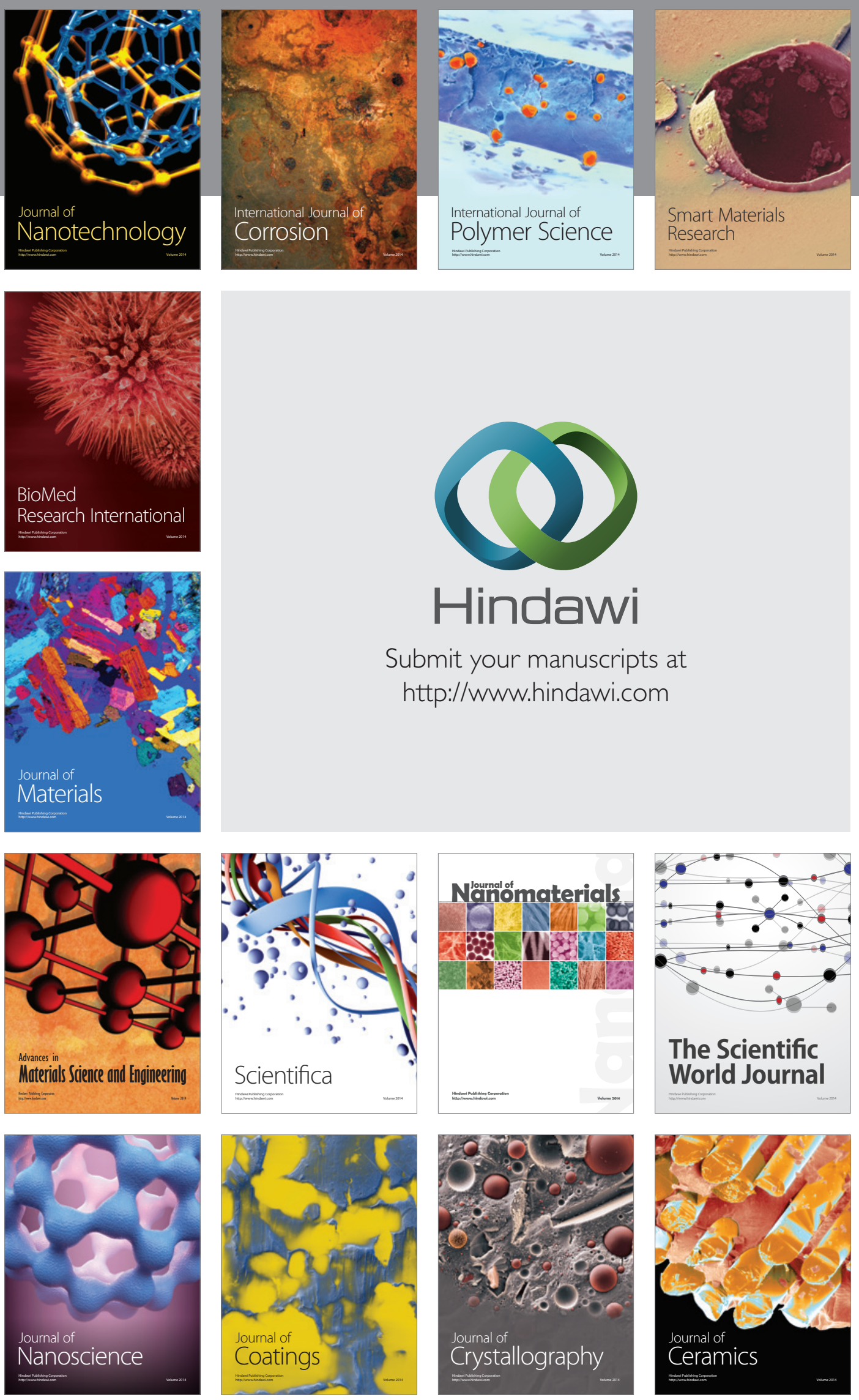

The Scientific World Journal

Submit your manuscripts at

http://www.hindawi.com

\section{World Journal}

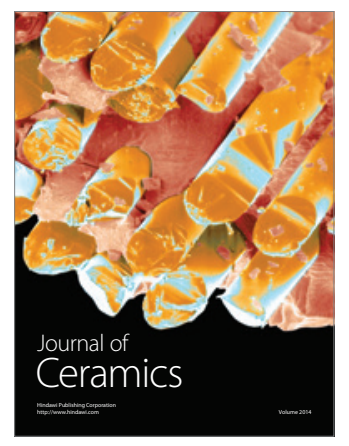

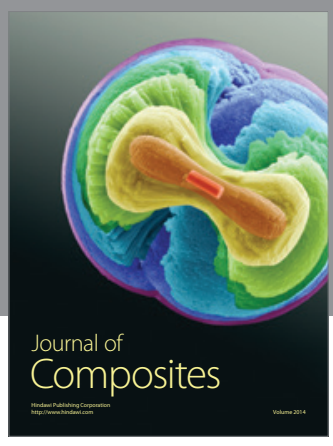
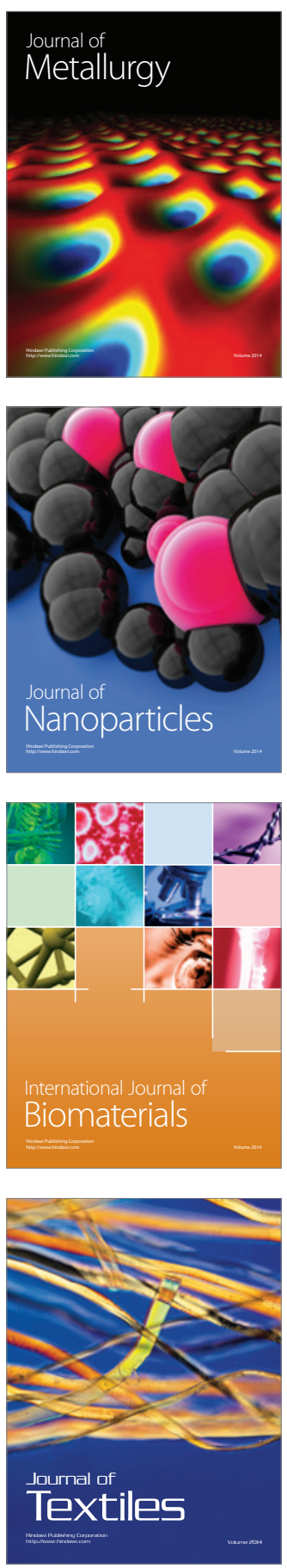